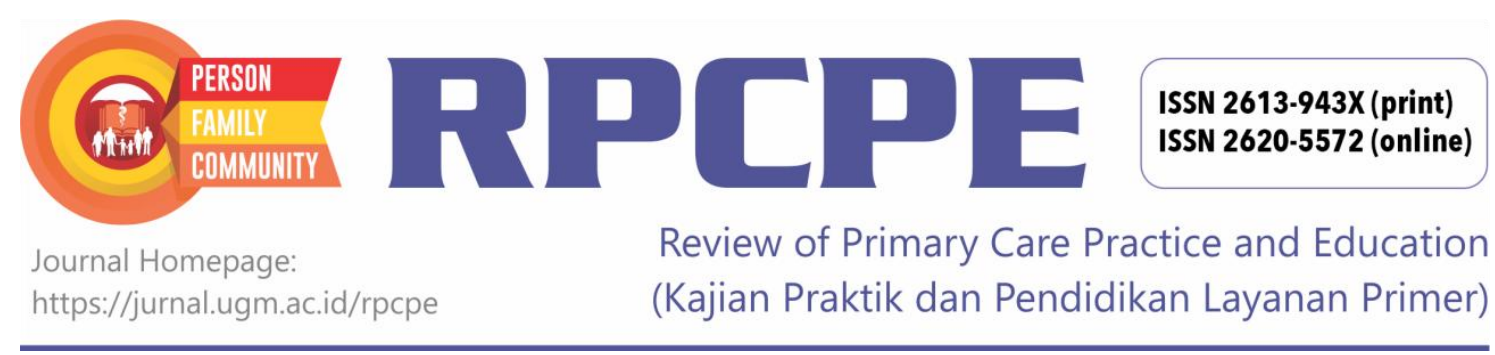

\title{
The Need for Palliative Care in Primary Health Care
}

\author{
Nita Arisanti ${ }^{1}$, Dany Hilmanto ${ }^{2}$, Elsa Pudji Setiawati ${ }^{1}$, Veranita Pandia ${ }^{3}$
}

\begin{abstract}
${ }^{1}$ Department of Public Health; Faculty of Medicine; Universitas Padjadjaran; Indonesia
${ }^{2}$ Department of Child Health; Faculty of Medicine; Universitas Padjadjaran; Indonesia

${ }^{3}$ Department of Psychiatry; Faculty of Medicine; Universitas Padjadjaran; Indonesia
\end{abstract}

Corresponding Author:

Nita Arisanti: Department of Public Health; Faculty of Medicine; Universitas Padjadjaran, Jalan Eykman No. 38 Bandung - 45363, Indonesia

Email: nita.arisanti@unpad.ac.id

To cite this article:

Arisanti N, Hilmanto D, Setiawati EP, Pandia V. The need for palliative care in primary health care. Rev Prim Care Prac and Educ. 2018; 1(3): 103-104.

\section{INTRODUCTION}

The change of population structure, the pattern of disease and life expectancy demands the improvement and changes in health services. From 2004 to 2015, the life expectancy in Indonesia increased from 68.6 years to 70.8 years and reached 72.2 years in 2030-2035. In 2017, the leading cause of premature death measured regarding Years of Life Lost (YLL) and the leading causes of Disability-Adjusted Life Year (DALYs) in Indonesia was cerebrovascular disease, tuberculosis, and traffic accidents. This data shows the tendency towards increasing the number of degenerative diseases and chronic diseases. Increasing the number of patients with chronic diseases and being terminal or endstage will require comprehensive and integrated health care.

\section{THE NEED FOR PALLIATIVE CARE}

Palliative care as one forms of comprehensive and integrated care aims to improve the quality of life for patients with active, progressive disease. The objective of care is to reduce pain and other symptoms. Based on the World Health Organization (WHO), palliative care is a service to improve the quality of life for patients and families with a terminal illness or life-threatening through the prevention and relief of suffering by early identification, good evaluation and the management of physical, psychosocial and spiritual pain ${ }^{1}$.

Initially, palliative care is more emphasized on patients with cancer, but by the change in the type of disease, palliative care is also delivered to non-malignant chronic diseases such as neurological disease, advanced lung disease, and frailty. At an advanced stage, patients with malignancies and chronic diseases not only experience with various physical problems but also psychosocial and spiritual problems that affect the patient's quality of life. Therefore, the care for patients with the end-stage disease is not only aimed at the fulfillment of physical symptoms but also the support for psychological, social and spiritual needs. Ideally, it should be conducted with an interdisciplinary approach and given at the beginning of the disease's course ${ }^{2}$.

The access to palliative care in ends of life is one of the patients' rights. Therefore it should be delivered into every level of health care for patients and family members. In some countries, palliative care is more frequent delivered in hospitals compare to primary health care, even though primary health care has a significant role in providing palliative care. Most families prefer to care for patients at home rather than in the hospital.

Integration of palliative care with health care systems is an important strategy to improve access to palliative care $^{2}$. The collaboration between health personnel of a multidisciplinary and interdisciplinary approach in all levels of healthcare facilities is needed. Healthcare should be provided either in the hospital by palliative specialists or facilities in primary health care by doctors, nurses, psychologists, families, social workers, spiritual service providers, pharmacists, and the public.

In Indonesia, palliative care has been introduced into health care system since 1989, through the National Cancer Control Program, even though palliative care became the agenda of the Indonesian government in 2007 with the issuance of Decree on Palliative Care Policy. In this decree, the implementation of palliative care can be delivered in several types of healthcare facilities, including palliative units in hospitals type B, C, D (non-educational hospital) and palliative unit in type B (hospital for education ) and type A hospitals ${ }^{3}$. 
The implementation of palliative care in Indonesia is still very limited to certain hospitals, even though doctors in primary care have great potential to offer such care to people in the community. Some of the factors contributing to the implementation are cultural and socioeconomic factors, patient and family perceptions, attitudes of service providers, lack of trained personnel, distribution of palliative care units, lack of consolidation and limited funds. As a result, patients with end-stage disease die in hospitals without receiving palliative care or dying at home with inadequate support ${ }^{3}$.

Based on these problems, there are the areas of the greatest challenge to provide integrated and accessible palliative care to all people in Indonesia. Integrated palliative care should be supported by policies, competent health personnel, adequate facilities, and good public/ community awareness. Every healthcare facility should have a policy or standard procedure for delivering palliative care. Palliative care may be integrated into the undergraduate medical and nursing curriculum. Health personnel can potentially play a role to educate patient and family members regarding palliative care. Collaboration and coordination between specialists in tertiary and secondary healthcare facilities to primary healthcare facilities is one strategy to implement integrated palliative care.

Palliative care should be financially accessible to all people. Palliative care is frequently funded with a mixed system of charitable, public and private payers. In most countries, palliative care is funded through the same system as mainstream health financing. All stakeholders may be considering those strategies to implement palliative care in Indonesia.

\section{REFERENCES}

1. World Health Organization. Knowledge into action palliative care. Cancer control. Geneva: World Health Organization, 2007; p.1-42.

2. Herce ME, Elmore SN, Kalanga N, Keck JW, Wroe EB, Phiri A, et al. Assessing and responding to palliative care needs in rural subSaharan Africa: Results from a model intervention and situation analysis in Malawi. PLoS One. 2014;9(10):1-17.

3. Ministry of Health Republic of Indonesia. Decree of the Minister of Health No. 812 Year 2007 about Palliative Care Policy. Jakarta: Ministry of Health Republic of Indonesia. 2007. 